\title{
Work-related Stress Management by Finnish Enterprises
}

\author{
Maritta KINNUNEN-AMOROSO ${ }^{1 *}$ and Juha LIIRA ${ }^{1}$ \\ ${ }^{1}$ Finnish Institute of Occupational Health, Finland \\ Received September 1, 2013 and accepted January 24, 2014 \\ Published online in J-STAGE February 28, 2014
}

\begin{abstract}
Work-related stress has become one of the major problems in working societies and it increases employees' risk of disease. Its importance has been emphasized also due to its' great socio-economic consequences. Different stress management and worksite interventions have been implemented, however, the actual practices in companies have been assessed little. The purpose of this study was to examine how enterprises in Finland manage work-related stress. An assessment of work-related stress methods was conducted in 40 enterprises acting in the metropolitan area of Finland in May 2010 by a questionnaire. The concept of work-related stress was well known by participants. Enterprises rarely had their own work-related stress management protocol even though all of the workplaces had experienced work-related stress at some point. The collaboration between the workplace and occupational health services varied. Companies easily placed the responsibility for work-related stress assessment and handling on occupational health services. Workplaces have to pay more attention to work-related stress and related issues. The easiest way to do this is to collaborate with occupational health services. Protocols for collaboration should be developed jointly using the available models which have been established as cost-effective.
\end{abstract}

Key words: Workplace, Work-related stress, Collaboration, Occupational health service, Management method

\section{Introduction}

Working conditions are affected by globalization and chances in work environment with new technologies and practices. Work-related stress has increased in workplaces because of performance requirements and competition-related changes in working life ${ }^{1,2}$. These psychosocial work environment changes have long been identified as an important risk factor in the health of the working population. Their relationship with various diseases has been showed in several studies, but probably more apparent are the vast socio-economic consequences manifested in absenteeism,

*To whom correspondence should be addressed.

E-mail: maritta.kinnunen-amoroso@ttl.fi

(C)2014 National Institute of Occupational Safety and Health labor turnover, loss of productivity and disability pension costs to the companies and to society ${ }^{2-7)}$.

Since the late 1990's, the WHO Network of Collaborating Centers in Occupational Health has supported a dedicated program of work on psychosocial factors and workrelated stress. Currently, part of the Network's work consists of focusing on the translation of existing knowledge into practice in the area of psychosocial risk management ${ }^{4}$.

The European social partners and the European Agency for Safety and Health at Work have tried to emphasize the importance of preventing and intervening stress factors and to recognize and handle these at different levels in workplaces $^{7}$. In Europe, an autonomous framework agreement on work-related stress was developed in 2004 and is now referred to as the EU's (European Union) Framework Agreement. Finnish social partners developed a corre- 
sponding local agreement and the Agency for Safety and Health at Work in Finland implemented it in $2007^{8,9}$.

Despite available research evidence, the level of knowledge of the harms of work related stress varies in workplaces. Preventive measures on reducing physical load are much more popular than measures taken against psychological overload. Recently new ways for psychosocial risk management in workplaces have been introduced ${ }^{10)}$. In the European survey of psychosocial risk management 35\% of the enterprises expressed their need for information and support to design and implement preventive measures ${ }^{11)}$.

In Finland, the most important collaborator in employees' health promotion is the occupational health services (OHS). The Finnish Occupational legislation clearly defines the roles and duties of OHS, which create collaboration and cooperation in matters concerning safety and health at work between OHS and enterprises ${ }^{12)}$.

To enforce collaboration between the workplace and OHS in Finland some modifications have been made in the Finnish Health Insurance Act. The practices related to the management, follow-up and early intervention of work capacity now have to be documented and jointly agreed by the workplace and the occupational health care provider in order to have higher reimbursement rates for preventive occupational health care from The Social Insurance Institution of Finland. This change aims at strengthening the effectiveness of occupational health services designed to promote work capacity and prevent disability ${ }^{13)}$. This national agreement takes into consideration the responsibility of the workplace and requires collaboration with occupational health services. Stress in work place is related to burn out and depression which is one major cause of work disability in Finland.

Due to the little information available on actual practices in the workplace on how the enterprises handle workrelated stress we wanted to investigate this with an email survey. There is also little knowledge on the collaboration between enterprises and occupational health services. The aim of this study was to assess the knowledge and activities relating to work-related stress in enterprises and what methods are used to handle it.

\section{Subjects and Methods}

The issue of work-related stress was previously investigated through interviews and self-completed questionnaires with occupational health 10 physicians and 8 nurses ${ }^{14)}$. The questionnaire for this study was formulated based on this earlier data. The Theory of Planned Behavior type of question formulation was used when developing the questionnaire on the experiences in the workplaces with questions targeted to both behavioral, normative and control beliefs ${ }^{15)}$. Respondent characteristics were determined through 5 questions: the enterprises' occupation area and size, the participants' profession, age and gender by multiple choice questions. The scale of the question were dichotomous type (yes, no, don't know).

The self-completed questionnaire consisted of 11 questions:

- Have you heard about the autonomous framework agreement on work-related stress signed by Europe UNICE / UEAPME, CEEP and the ETUC and that the Finnish social partners have made a local agreement about it, which they have implemented?

- Is the concept of work-related stress well known to you?

- Has work-related stress ever been raised in your enterprise?

- Has your enterprise had contact with your OHS supplier regarding work-related stress?

- Has your OHS supplier contacted your company regarding work-related stress?

- Does your enterprise collaborate with your OHS supplier in matters relating to work-related stress and can the collaboration be improved somehow?

- Whose responsibilities/duties include the topic of workrelated stress?

- Who needs to collaborate on issues of work-related stress?

- Does your company have a common protocol to assess and handle work-related stress and if so what kind of?

- Does your company's administration support intervening on work-related stress?

- Have you participated in any kind of training consisting of evaluating psychological overload, well-being in the work community and work-related stress?

The questionnaire was accompanied by a cover letter which explained that the results would be analyzed anonymously group level. The questionnaires were returned anonymously to the lead researcher. Participants were not sent any reminders. Results were calculated in percentages and figured in tables by first author. Participants were informed about the content and conduct of the study. All responses were confidential reported in group level.

\section{Results}

The preliminary email invitation to participate in the survey was sent to random sample of 565 OHS client com- 
panies in the Finnish metropolitan area in May 2010. The invitation letter was send to the OHS contact person or to human resource manager in the companies who would know of the stress management practices in their companies. During two weeks 57 replied by email that they were willing to participate to survey sending their email addresses. All 57 were sent questionnaires by email with a more accurate invitation letter. Of these, 40 participants responded with response rate $70 \%$. The participants were stratified according to their profession, age and company size.

The background characteristics of the participants are presented in Table 1.

Both private and public organizations as also industries and services were represented among the respondents (Table 2).

The concept of work-related stress was well known to most of the participants (98\%). The EU's Framework Agreement on work-related stress was not known so well. Work-related stress had been experienced in all of the workplaces surveyed.

The participants' enterprises had contacted OHS suppliers regarding work-related stress in $64 \%$ of the cases and the OHS producers contacted the enterprises regarding work-related stress in $38 \%$ of the cases (Figs. 1 and 2).

OHS and enterprises had collaborated on issues relating to work-related stress in $65 \%$ of all cases. The administration supported intervening on work-related stress in $43 \%$ of cases, but in $33 \%$ of cases there was no administration support for interventions (Figs. 3 and 4).

The collaboration between workplace and OHS could be improved according to $70 \%$ of the respondents. The main issue on which to improve was increasing active communication between the workplace and OHS and to form regular meeting practices. The respondents hoped
Table 1. Demographic data of the study participants

\begin{tabular}{lc}
\hline Variable & Total n (\%) \\
\hline mean n (\%) & 40 \\
gender female & $38(97.4)$ \\
Age (in categories, n (\%)) & \\
$<40$ & $9(22.5)$ \\
$41-50$ & $18(45)$ \\
$51-60$ & $11(27.5)$ \\
$>61$ & $2(5)$ \\
Enterprize size & \\
$<50$ workers & $20(50)$ \\
$51-100$ workers & $10(25)$ \\
$>101$ workers & $10(25)$ \\
Participants' working position* & \\
Occupational health contact person & $23(57.5)$ \\
Human resources & $18(45)$ \\
Occupational safety and health & $13(32.5)$ \\
Immediate supervisor & $3(7.5)$ \\
Higher managerial position & $2(5)$ \\
Administration & $8(20)$ \\
Shop steward & $1(2.5)$ \\
\hline
\end{tabular}

*The same person may have different roles in the company and has been able to answer this question in multiple sites.

the OHS would take a more active role in communicating with workplaces. The respondents recognized that communication could be lacking sometimes due to employees who do not want stress issues to be discussed with the employer. However, respondents wished for more transfer of information from OHS to supervisors about employees' situations. According to respondents, absenteeism caused by work-related stress or burn out should be actively monitored by OHS and preventive actions should be undertaken. Respondents also requested education and information to the entire work community. A need for a psychological

Table 2. The branch of business of the respondents

\begin{tabular}{lr}
\hline Industry & 17.5 \\
Construction & 2.5 \\
Wholesale and retail trade (motor vehicles and personal and household goods) & 12.5 \\
Accommodation and catering & 5.0 \\
Transport, storage and communication & 5.0 \\
Financing & 7.5 \\
Realestate, renting and business activities, business services & 15.0 \\
Public administration and defense, compulsory social security & 2.5 \\
Education & 2.5 \\
Health and social services & 2.5 \\
Other community, social and personal services & 22.5 \\
Industry unknown & 5.0 \\
\hline
\end{tabular}




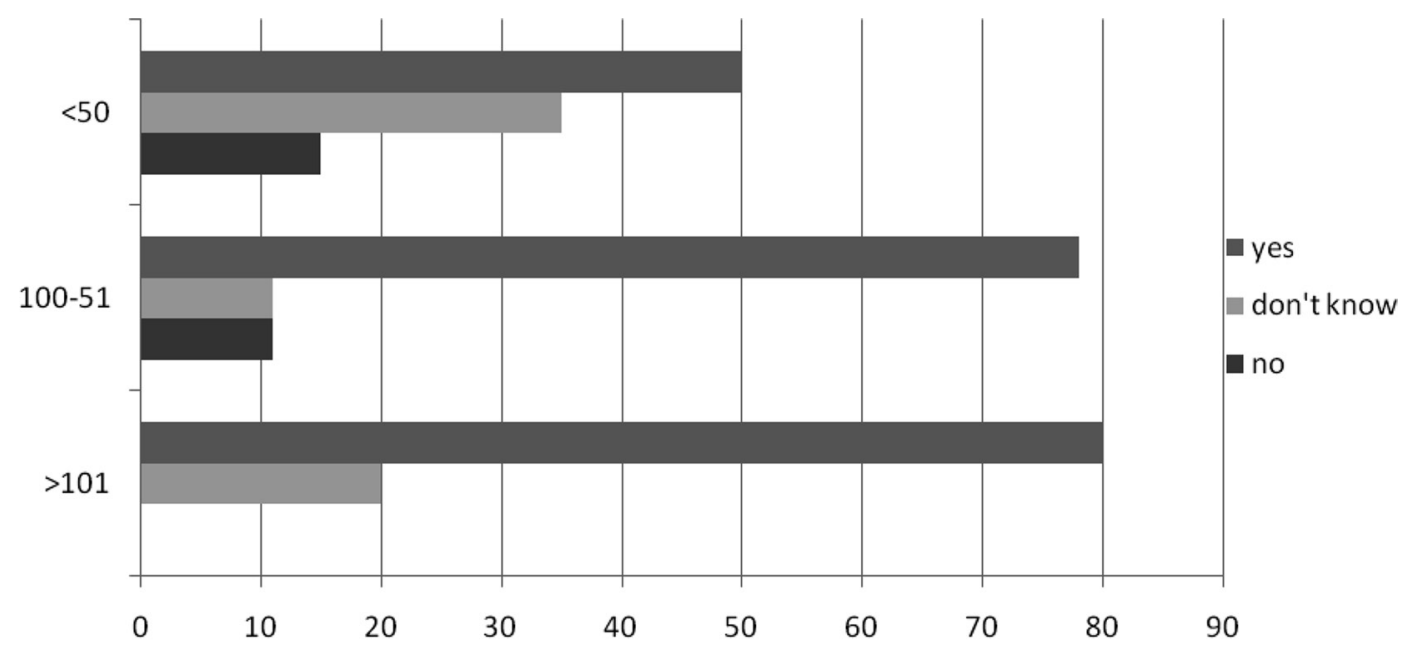

Fig. 1. Contact activity in work-related stress: have you OHS take contact to your enterprise about work-related stress? The results in percent. Workplace size: under 50 workers, 51-100 workers, over 101 workers.

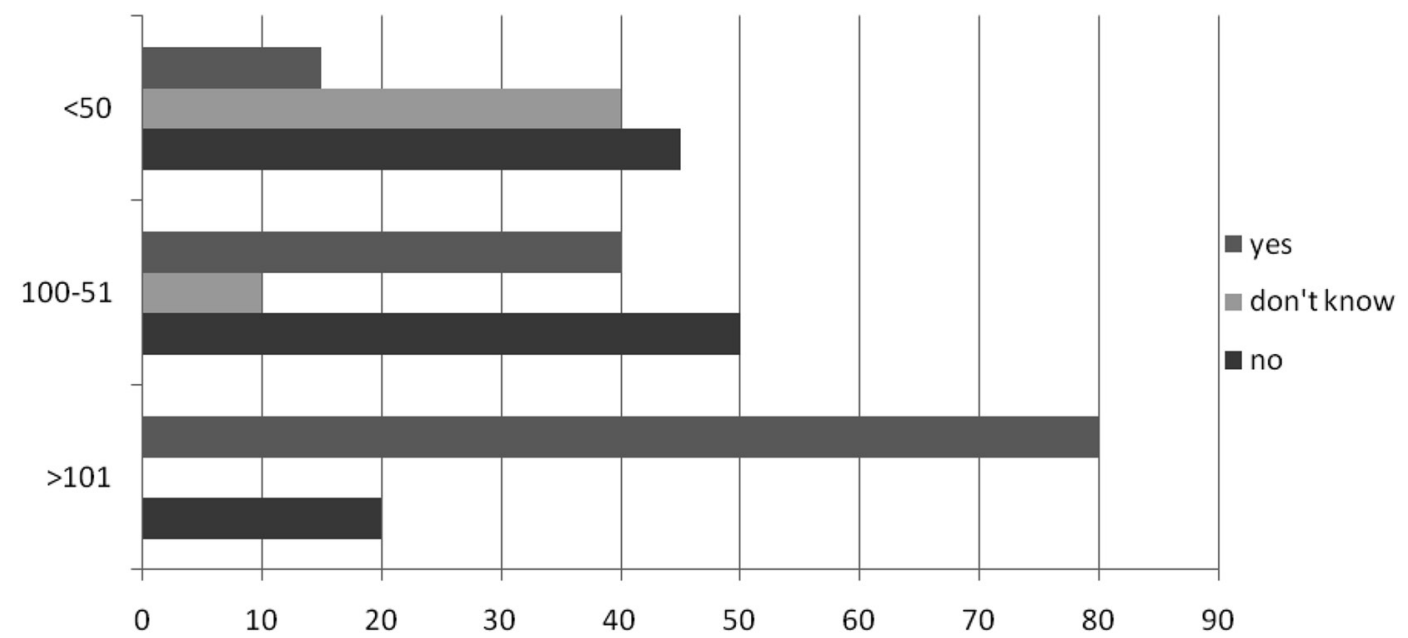

Fig. 2. Contact activity in work-related stress: have your enterprise taken contact to OHS about work-related stress? The results in percent. Workplace size: under 50 workers, 51-100 workers, over 101 workers.

survey of the entire organization and a functional early intervention model was identified. Consultations on stress with OHS professionals, especially with the occupational nurse, were also seen as important. The participation of the administration on information sessions relating to workrelated stress was seen as useful but difficult to organize.

Only $10 \%$ of respondents reported that their enterprises had their own work-related stress management model and only one participant answered the open question about the content of the model; this company has an early intervention model, performance reviews and employee satisfaction survey. Twenty percent of larger enterprises had a stress management model.

In general, dealing with work-related stress was as- sessed as tasks of occupational physicians and nurses (93\%). Eighty percent of respondents identified the occupational psychologist as relevant OHS professional dealing with work-related stress. The respondents saw the responsibility of dealing with stress belonging to the enterprise administration (85\%). The human resources department (HR), supervisors and occupational safety and health were also seen as having the responsibility in $70-80 \%$ of the companies. Collaboration with OHS was seen important by $93 \%$ of respondents and collaboration within enterprises by $75 \%$. Respondents considered that collaboration inside enterprises on stress should be the responsibility of the administration (83\%), supervisors (68\%), HR and occupational safety and health $(65 \%)$ and 


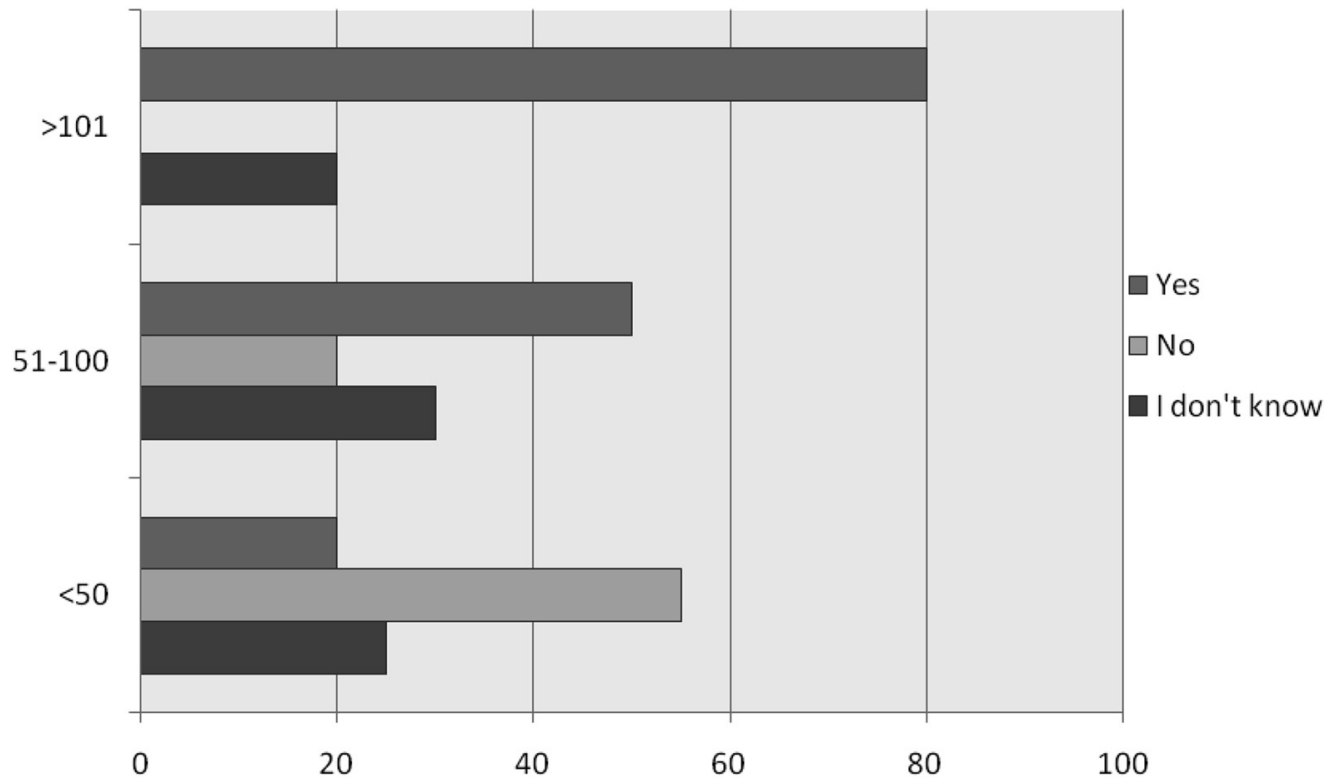

Fig. 3. Does the administration of your enterprise support the interventions on work-related stress? The results in percent. Workplace size: under 50 workers, 51-100 workers, over 101 workers.

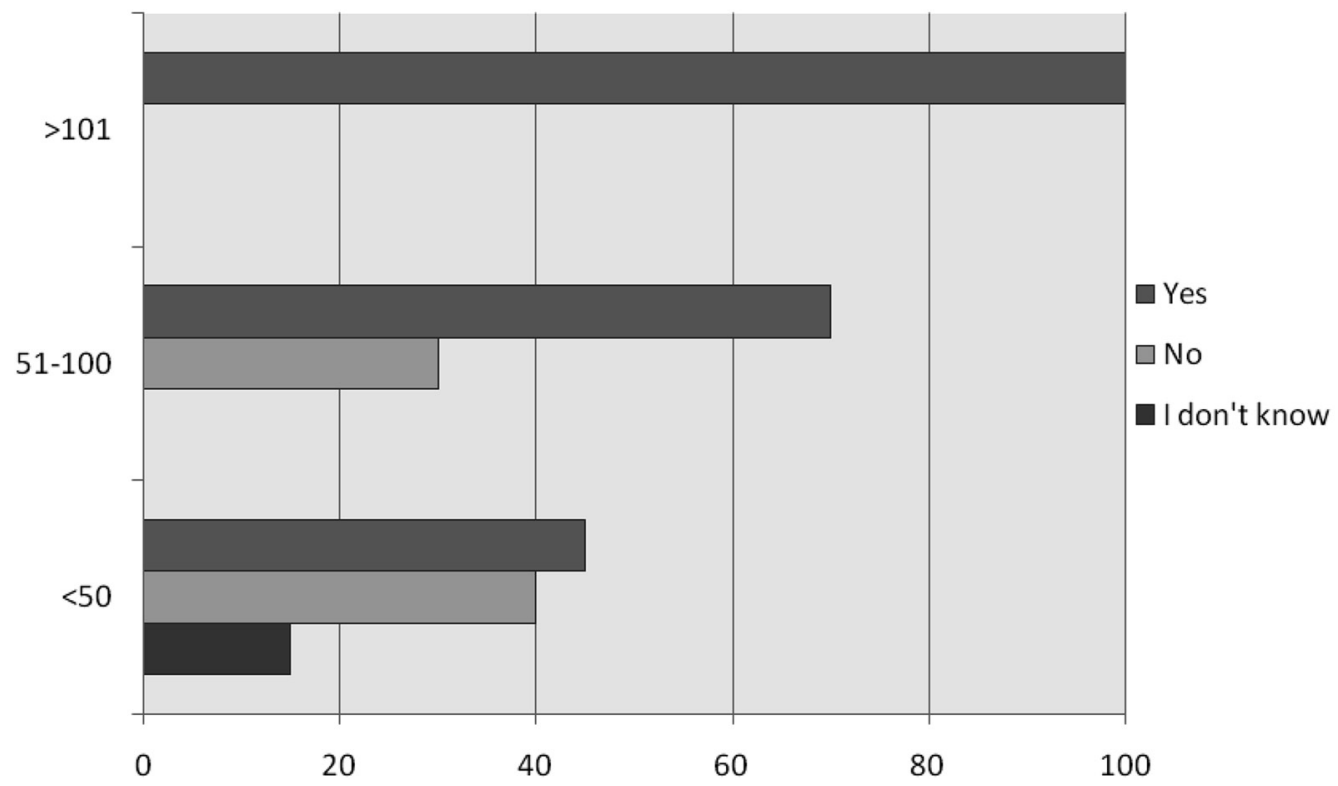

Fig. 4. Does your enterprise collaborate on work-related stress with your OHS?

The results in percent. Workplace size: under 50 workers, 51-100 workers, over 101 workers.

employees (63\%) (Figs. 5 and 6).

Nearly all respondents were interested in participating in education relating to handling work-related stress. Less than half of them (44\%) had attended education regarding any kind of assessment of psychosocial overload, work community well-being, work-related stress or other related topics.

\section{Discussion}

Work-related stress was well known to all participants in this study. There were no differences in the experience of work-related stress between different sized workplaces or different field of business. The own work-related stress management model were lacking in all size of enterprises. The communication and cooperation between the work- 


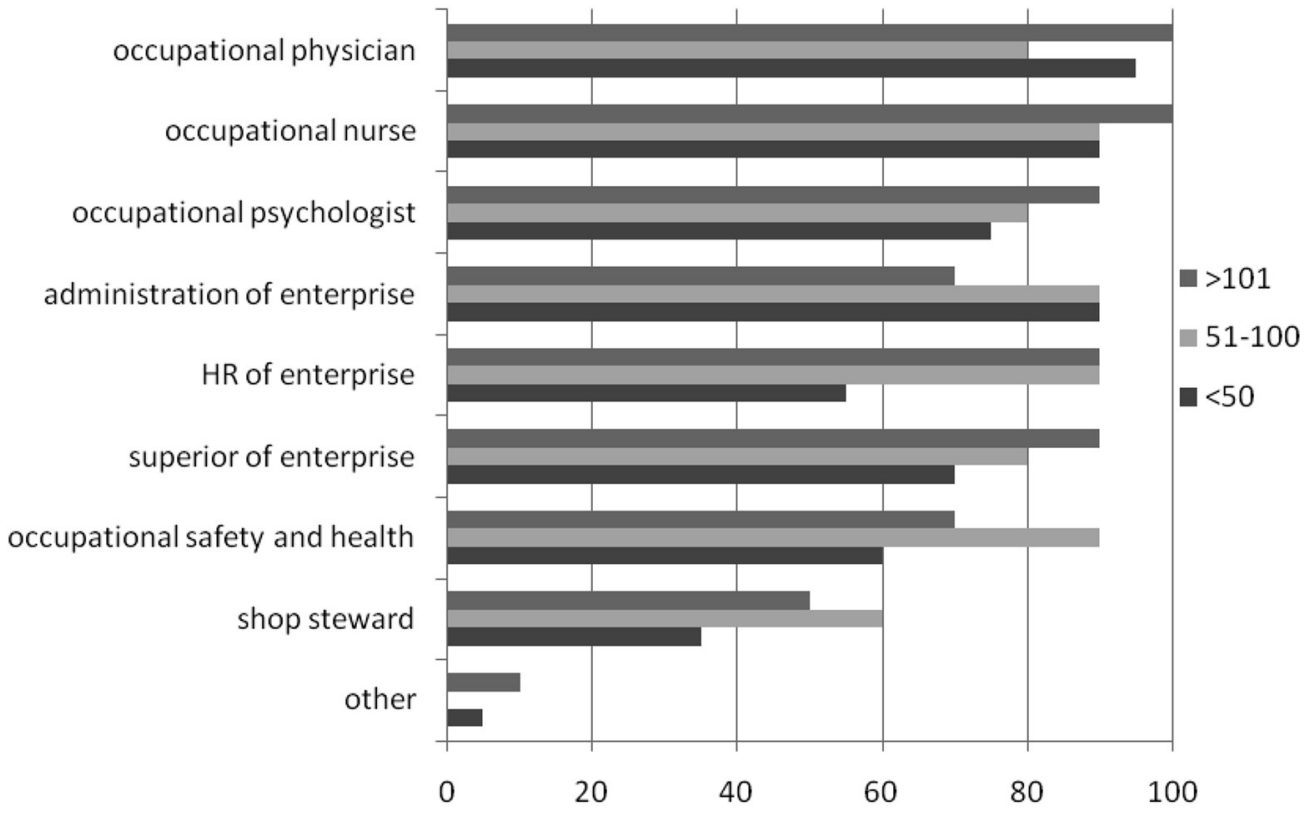

Fig. 5. Tasks and responsibilities: whose tasks include work-related stress?

The results in percent. Workplaces size: under 50 workers, 51-100 workers, over 101 workers (Selecting multiple options were possible).

internally within the enterprise occupational health service administration of enterprise HR of enterprise superior of enterprise occupational safety and health shop steward own workers own insurance external expert

others

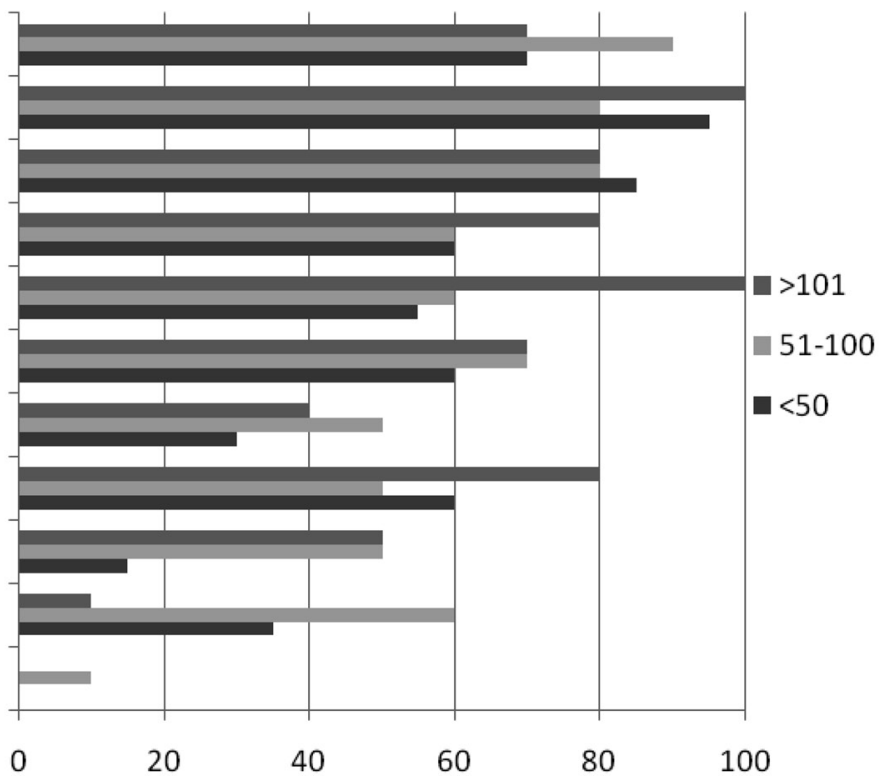

Fig. 6. Tasks and responsibilities: Who should collaborate on work-related stress?

The results in percent. Workplace size: under 50 workers, 51-100 workers, over 101 workers.

place and OHS varied greatly according to the size of the enterprise. The situation regarding the communication and collaboration between OHS and workplaces seemed to be most favorable in larger companies (over 100 persons). The enterprises' administrations supported interventions on work-related stress more often than in smaller compa- nies. Traditional occupational risks are higher and their management weaker in small and medium size enterprises. However employees at small companies may experience less stress at work due to direct contacts within the company.

Respondents' views on who was responsible for han- 
dling work-related stress in OHS and enterprises varied. The OHS was seen as responsible for work-related stress most in the smallest and biggest companies. In the companies that were categorized as middle size (between 51-101 workers) the importance of collaboration with administration, HR and occupational health and safety department in work-related stress issues was emphasized. In the larger enterprises, respondents favored OHS collaboration with the HR department and supervisors in stress issues, leaving administration in the background. In contrast, respondents from smaller companies attributed the responsibility to the administration and the OHS.

It is possible that in smaller workplaces HR matters are included in the administration's responsibilities as they do not have an HR department. In larger workplaces the administration may be seen as too remote from this kind of decision, thus respondents may have assigned the responsibility to the HR department and supervisors.

Collaboration with OHS was seen as important. The need for active communication between the workplace and OHS, with regular meetings was highlighted. Respondents expected preventive activities by OHS in workplaces. It seems that there is inadequate knowledge of work-related stress prevention actions in workplaces and OHS support is needed. This supports previous research results ${ }^{16}$.

Different reviews of job stress interventions suggest that the common approach to combating job stress is to focus on the stressed individual without due consideration of the direct impacts of working conditions on health ${ }^{17-21)}$. In the USA in $80^{\prime}$ health promotion activities were assessed in private work places. Stress management activities were provided at $27 \%$ of surveyed work sites in the country. The frequency of activities provided varied by industry type and by region of the country ${ }^{22}$. The situation was similar in our study - work-related stress management activities have been conducted in only a few enterprises. As the response rate to mail questionnaire in first round of our study was low there might be quite few work places with active stress management programs in Finland.

Psychosocial risks like work-related stress have been evaluated also to be important part of occupational safety and health (OSH). The guidance on dealing with psychosocial risk factors by occupational safety and health has been published by International organizations and EU agencies, which based on risk management approach. The best practices in real life have been reviewed in Europe and in these different assessments on EC (European Community) regulatory standards on practice have been found out the gap between policy and practice due to a lack of clarity related to regulatory frameworks and guidance on the management of psychosocial risks, but also barriers related to enterprise characteristics and management at enterprise level. The level of acknowledgement, awareness and prioritization of these issues varies between countries association with a lack of expertise, research and appropriate infrastructure. There has found out low prioritization of preventive actions at enterprise level. There is a need for systematic and effective policies to prevent and control psychosocial risks at work, linked to companies' management practices with tools that support organizations at the organizational level.

In the secondary analysis of ESENER study (European Survey of Enterprises on New and Emerging Risks) revealed that the most important driver of managing workrelated stress is OSH management, and the most important barriers were lack of the technical support and guidance and lack of resources. Good OSH management turned out to be the strongest predictor for all procedures and measures to deal with psychosocial risks, independent of the size, sector, status, and country of origin of the enterprises. They found out a need for continuous support and further knowledge on how to establish good psychosocial risk management procedures for work-related stress ${ }^{11)}$.

These results support our findings when there is a lack of knowledge about work-related stress and here the OHS support is needed ${ }^{11)}$.

There is some information on interventions that might be successful at workplaces. Workplace health promotion programs have been conducted that have tested different interventions of health education, collaboration and organizational change ${ }^{23)}$. In these studies activities have included workplace assessment, facilitating communication and agreement among stakeholders and conflict resolution and medical training ${ }^{24-28)}$. The results of these studies suggested these interventions had a positive effect on employee health ${ }^{29,30)}$. These earlier findings could be used in planning, making use of the data based on experience. The interventions involving employees, health practitioners and employers working together, and implementing modifications to the content of work, are shown more effective than other interventions ${ }^{31-33)}$. However, when planning worksite interventions, the administration's and entire enterprise's commitment, confidence in OHS, evaluation and feedback about the program are needed ${ }^{25,34-36)}$.

The study has some limitations. Firstly, the questionnaire was developed for the needs of this study and was not tested for validity or reliability. Also, the participants were invited to participate in the study by email in a given 
time with no reminders, which may limit the number of participants. In addition, the study population was determined at the enterprise level, therefore we could not send the questionnaire to those best aware of the company's situation. The same person may have different roles in the company and asked about the role he/she has been able to answer this question in multiple sites. This led to heterogenous distribution of the positions of respondents in the companies. Most of participants were women which may reflect gender distribution in occupational health issues in the companies.

Studying enterprises' practices is challenging because the different structures within and resources available to companies may influence the responses. Contracts with different OHS suppliers can also influence the responses. When assessing practices, different understandings of work-related stress as a concept can also cause variation. The assessment of the situation is based on subjective views that vary from one individual and situation to another. This study involved only those who were willing to participate, who may well be a highly motivated group. However, as the information in the questionnaire was impersonal, we may expect that the respondents reported the situation as accurately as possible.

The OHS alone can't change the working conditions and the enterprises need more information on work related stress and what they can do about it. The enterprises should be willing need to affect to work-related stress and prioritize preventive actions at enterprise level $1^{11,16,29,30)}$. The collaboration between workplace and OHS could be improved increasing active communication between the workplace with regular meeting. No one is the single owner of the problem of work-related stress and actions should be taken in cooperation with OHS, OSH and enterprises.

Future research should to examine this improvement of communication between workplace and OHS.

There is also a need for future studies to evaluate interventions that include workplace prevention activities. Future research should also include economic evaluation, which can assist employers in making decisions about which intervention to implement.

\section{Acknowledgements}

This work was supported by the Finnish Ministry of Social Affairs and Health and the Finnish Medical Association. No other funding agencies had a part in conducting this study. The authors also thank the Finnish Association of Occupational Health Physicians and The Finnish
Institute of Occupational Health to collaboration to make possible this study. The authors also thank Salla Atkins for participating in the proofreading of this article.

\section{References}

1) EU-OSHA, European Agency for Safety and Health at Work (2012) European Survey of Enterprises on New and Emerging Risks: managing safety and health at work. European Risk Observatory report 2012. https:// osha.europa.eu/en/publications/reports/esener1_osh_ management. Accessed January 7, 2012.

2) EU-OSHA European Agency for Safety and Health at Work (2012) Management of occupational safety and health: analysis of data from the European Survey of Enterprises on New and Emerging Risks. (ESENER), Publications Office of the European Union, Luxembourg 2012. https:// osha.europa.eu/en/publications/reports/management-ofoccupational-safetyand-health-analysis-of-data-from-theesener/view. Accessed January 7, 2012.

3) Leka S, Kortum E (2008) A European framework to address psychosocial hazards. J Occup Health 50, 294-6. [Medline] [CrossRef]

4) Cox T, Griffiths A, Rial-Gonzales E (2000) Research on work-related stress. Office for Official Publications of the European Communities, Luxembourg 2000. http://osha. europa.eu/en/publications/reports/203 Accessed January 7, 2012.

5) de Smet P, Sans S, Dramaix M, Boulenguez C, de Backer G, Ferrario M, Cesana G, Houtman I, Isacsson SO, Kittel F, Ostergren PO, Peres I, Pelfrene E, Romon M, Rosengren A, Wilhelmsen L, Kornitzer M (2005) Gender and regional differences in perceived job stress across Europe. Eur J Public Health 15, 536-45. [Medline] [CrossRef]

6) Semmer NK (2006) Job stress interventions and the organization of work. Scand J Work Environ Health 32, 515-27. [Medline] [CrossRef]

7) European Agency for Safety and Health at Work (2002) Prevention of psychosocial risks and stress at work in practice. Office for Official Publications of the European Communities, Luxembourg 2002.

8) UEAPMEImplementation of the ETUC1/UNICEUEAPME/CEEP Framework agreement on Work-related Stress Yearly Joint Table summarising ongoing social partners activities 2006. http://www.ueapme.com/docs/ joint_position/Joint_Table_Implementation_Stress_2006. pdf. Accessed January 7, 2012.

9) UEAPMEImplementation of the European autonomous framework agreement on work-related stress. Report by European social partners adopted at the social dialogue committee on 18 June 2008. http://www.ueapme.com/ IMG/pdf/Stress_Final_Implementation_report_231108.pdf. Accessed January 7, 2012.

10) Leka S, Cox T (2008) PRIMA EF Guidance on the 
European Framework for Psychosocial Risk Management. A resource for employers and worker representatives. Protecting workers' healthseries No.9 WHO 2008. http:// www.who.int/occupational_health/publications/PRIMAEF\%20Guidance_9.pdf. Accessed August 30, 2010.

11) Drivers and barriers for psychosocial risk management: An analysis of the findings of the European Survey of Enterprises on New and Emerging Risks (ESENER) (2013) https://osha.europa.eu/en/publications/reports/driversbarriers-psychosocial-risk-management-esener. Accessed November 2, 2013.

12) Occupational Health Care Act $1383 / 2001$ http://www. finlex.fi/fi/laki/kaannokset/2001/en20011383.pdf. Accessed June 30, 2012.

13) The Social Insurance Institution of Finland http://www. kela.fi/in/internet/liite.nsf/NET/250111135142SP/\$File/ Ty\%C3\%B6nantajakirje_valmis.pdf?OpenElement. Accessed June 30, 2012.

14) Kinnunen-Amoroso M (2011) Finnish occupational physicians' and nurses' experience of work related stress management: a qualitative study. Ind Health 49, 774-8. [Medline] [CrossRef]

15) Ajzen I (1991) The theory of planned behavior. Organizational behavior and human decision prosesses 50, 179-211. [CrossRef]

16) Kinnunen-Amoroso M, Liira J (2013) Management of work-related stress by Finnish occupational physicians. Occup Med (Lond) 63, 361-4. [Medline] [CrossRef]

17) Noblet A, Lamontagne AD (2006) The role of workplace health promotion in addressing job stress. Health Promot Int 21, 346-53. [Medline] [CrossRef]

18) Murta SG, Sanderson K, Oldenburg B (2007) Process evaluation in occupational stress management programs: a systematic review. Am J Health Promot 21, 248-54. [Medline] [CrossRef]

19) Reynolds S (2000) Interventions: what works, what doesn't? Occup Med (Lond) 50, 315-9. [Medline] [CrossRef]

20) Lamontagne AD, Keegel T, Louie AM, Ostry A, Landsbergis PA (2007) A systematic review of the jobstress intervention evaluation literature, 1990-2005. Int J Occup Environ Health 13, 268-80. [Medline] [CrossRef]

21) van der Klink JJ, Blonk RW, Schene AH, van Dijk FJ (2001) The benefits of interventions for work-related stress. Am J Public Health 91, 270-6. [Medline] [CrossRef]

22) Fielding JE (1989) Work site stress management: national survey results. J Occup Med 31, 990-5. [Medline] [CrossRef]

23) Mikkelsen A, Saksvik PO (1999) Impact of a participatory organizational intervention on job characteristics and job stress. Int J Health Serv 29, 871-93. [Medline] [CrossRef]

24) de Boer AG, van Beek JC, Durinck J, Verbeek JH, van Dijk FJ (2004) An occupational health intervention programme for workers at risk for early retirement; a randomised controlled trial. Occup Environ Med 61, 924-9. [Medline]
[CrossRef]

25) Karasek RA (1992) Stress prevention through work reorganization. A summary of 19 international case studies. ILO Conditions of Work Digest. Preventing Stress at Work. 11, 23-42.

26) van Oostrom SH, Anema JR, Terluin B, de Vet HC, Knol DL, van Mechelen W (2008) Cost-effectiveness of a workplace intervention for sick-listed employees with common mental disorders: design of a randomized controlled trial. BMC Public Health 8, 12. [Medline] [CrossRef]

27) Chapman LS American Journal of Health Promotion Inc (2005) Meta-evaluation of worksite health promotion economic return studies: 2005 update. Am J Health Promot 19, 1-11. [Medline]

28) LaMontagne AD, Keegel T, Vallance D (2007) Protecting and promoting mental health in the workplace: developing a systems approach to job stress. Health Promot J Austr 18, 221-8. [Medline]

29) Gunnarsson K, Andersson IM, Rosén G (2010) Systematic Work Environment Management: experiences from implementation in Swedish small-scale enterprises. Ind Health 48, 185-96. [Medline] [CrossRef]

30) Kirsten W (2010) Making the link between health and productivity at the workplace - a global perspective. Ind Health 48, 251-5. [Medline] [CrossRef]

31) van Oostrom $\mathrm{SH}$, van Mechelen $\mathrm{W}$, Terluin $\mathrm{B}$, de Vet HC, Anema JR (2009) A participatory workplace intervention for employees with distress and lost time: a feasibility evaluation within a randomized controlled trial. J Occup Rehabil 19, 212-22. [Medline] [CrossRef]

32) Carroll C, Rick J, Pilgrim H, Cameron J, Hillage J (2010) Workplace involvement improves return to work rates among employees with back pain on long-term sick leave: a systematic review of the effectiveness and costeffectiveness of interventions. Disabil Rehabil 32, 607-21. [Medline] [CrossRef]

33) Michie S, Williams S (2003) Reducing work related psychological ill health and sickness absence: a systematic literature review. Occup Environ Med 60, 3-9. [Medline] [CrossRef]

34) Shaw W, Hong QN, Pransky G, Loisel P (2008) A literature review describing the role of return-to-work coordinators in trial programs and interventions designed to prevent workplace disability. J Occup Rehabil 18, 2-15. [Medline] [CrossRef]

35) Harden A, Peersman G, Oliver S, Mauthner M, Oakley A (1999) A systematic review of the effectiveness of health promotion interventions in the workplace. Occup Med (Lond) 49, 540-8. [Medline] [CrossRef]

36) Pelletier KR (2001) A review and analysis of the clinicaland cost-effectiveness studies of comprehensive health promotion and disease management programs at the worksite: 1998-2000 update. Am J Health Promot 16, 107-16. [Medline] [CrossRef] 